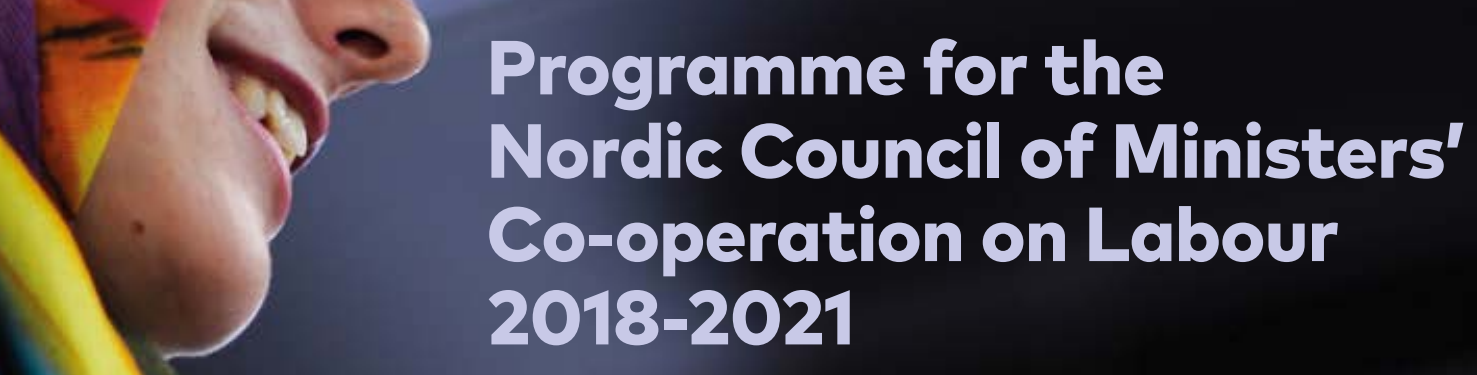

III) Nordic Council of Ministers 


\title{
Programme for the Nordic Council of Ministers' Co-operation on Labour 2018-2021
}

\author{
ANP 2018:713 \\ ISBN 978-92-893-5427-1 (PRINT) \\ ISBN 978-92-893-5428-8 (PDF) \\ ISBN 978-92-893-5429-5 (EPUB) \\ http://dx.doi.org/10.6027/ANP2018-713 \\ (C) Nordic Council of Ministers 2018 \\ Layout: Gitte Wejnold \\ Cover photo: Unsplash.com \\ Print: Rosendahls \\ Printed in Denmark
}

\section{Nordic co-operation}

Nordic co-operation is one of the world's most extensive forms of regional collaboration, involving Denmark, Finland, Iceland, Norway, Sweden, the Faroe Islands, Greenland, and Åland.

Nordic co-operation has firm traditions in politics, the economy, and culture. It plays an important role in European and international collaboration, and aims at creating a strong Nordic community in a strong Europe.

Nordic co-operation seeks to safeguard Nordic and regional interests and principles in the global community. Shared Nordic values help the region solidify its position as one of the world's most innovative and competitive.

\section{Nordic Council of Ministers}

\section{Nordens Hus}

Ved Stranden 18

1061 Copenhagen $\mathrm{K}$

www.norden.org

Download Nordic publications at www.norden.org/nordpub 


\section{Programme for the Nordic Council of Ministers' Co-operation on Labour 2018-2021}




\section{Contents}

Nordic Council of Ministers' co-operation programmes 6

About the co-operation programme on labour

Strategic focus areas 8

Focus Area 1

Focus Area 2

Focus Area $3 \quad 14$

Focus Area 4

Co-operation with the EU and other international actors 17

$\begin{array}{ll}\text { Organisation in the sector } & 18\end{array}$

Nordic Institute for Advanced Training in

Occupational Health - NIVA 20

Implementation of the co-operation programme 22 


\section{Nordic Council of Ministers' co-operation programmes}

The Nordic Council of Ministers cooperation programme on labour describes key political challenges and prioritisations in the sector for the period 2018-2021. The aim of the cooperation programme is to establish the strategic focus of the formal Nordic inter-governmental co-operation. The programme provides an overarching description of the focus areas where concrete initiatives and projects can be set up. The co-operation on labour involves the Nordic countries and the Faroe Islands, Greenland and Åland, and concerns employment and the labour market, as well as the work environment (occupational health and safety) and labour law.

The co-operation programme serves as policy in the sector, and is to be considered in relation to other policy documents in the Nordic co-operation. The co-operation programme supports both the statement of the Nordic prime ministers in 2016 about making the Nordic region the most integrated region in the world, and the vision of the Nordic Ministers for Co-operation, Together We Are Stronger, adopted in 2014. In addition, the cross-sector strategies of the Nordic Council of Ministers - gender equality, sustainable development, children and young people, integration, and disabilities - will be integrated in the programme.

In 2016 the former Danish minister and EU Commissioner, Poul Nielson, carried out a strategic examination of working life on behalf of the Nordic Council of Ministers for Labour (MR-A). The examination resulted in the report, Working life in the Nordic region: Challenges and proposals, and was discussed at the MR-A's meeting in November 2016. The theme, analyses and proposals in the report, and MR-A's conclusions during the meeting, together form an important basis for this cooperation programme.

Co-operation within the labour sector is largely focused on investigating, analysing and discussing similarities and differences between the Nordic countries in terms of measures, as well as results and best practice in relation to common challenges. The co-operation can provide inspiration to national policy development in the individual countries, and enables coordination of views in the areas where the countries can achieve more together than individually, on occasions when this is deemed relevant and generates Nordic benefit. 


\section{ABOUT THE CO-OPERATION PROGRAMME ON LABOUR}

Labour and working life play a key role in the development of the Nordic welfare societies, for business, and for the individual. The common labour market comprises a cornerstone in the Nordic co-operation. A large, skilled workforce is our most important resource, and forms the foundation for a competitive Nordic labour market and for the development of the Nordic welfare societies. The Nordic region distinguishes itself internationally by having a high level of education for both women and men.

At the same time, the Nordic labour markets are facing major challenges because of, for example, demographic change, increased globalisation, and international competition. Rapid technological development has consequences for labour, in terms of demand, skills requirements, organisation and content. This development creates a variety of new opportunities, but also risks generating considerable challenges.

The co-operation programme on labour 2018-2021 identifies several important challenges relating to labour, and shows how the Nordic co-operation can help to address these. The co-operation programme formulates important conditions for the Nordic co-operation on labour. In the programme, themes and issues are presented that will form a key part in discussions and exchange of experiences between the Nordic countries, and that form the basis for acquisition of knowledge and examples of best practice during the four-year period.

The governments in all Nordic countries work continuously to promote a wellfunctioning labour sector and to promote sustainable growth and employment. The Nordic co-operation gives the governments valuable information and inspiration for this work.

During the programme period, the co-operation on labour will mainly concentrate on the following focus areas:

- Strengthen the matching between supply and demand regarding a skilled workforce and increase participation in the labour market, particularly for vulnerable groups;

- Ensure a healthy work environment for both women and men, such as by preventing work-related health problems and workplace injuries, and abolishing unacceptable working conditions;

- Ensure a good balance between employee protection and flexibility, and utilise the Nordic tripartite model for labour;

- Strengthen integration, equal opportunities, and mobility on the Nordic labour market.

The co-operation programme was adopted on 28 November 2017, comes into effect on 1 January 2018, and runs until the end of 2021. 


\section{Strategic focus areas}

During the programme period, the focus of the co-operation on labour will primarily be on a series of objectives aimed at addressing the long-term challenges and opportunities relating to the Nordic labour market. The challenges facing Nordic labour in the future include the internationalisation of the labour market, digitalisation, and the entry of the sharing economy, and the effects of these on employment forms, degree of organisation, and work environment. Automation and robotisation involve a risk of jobs disappearing or changing.

Key challenges in the labour sector are increasing inequalities, low-wage competition and marginalisation, and issues of skills supply and in-service training. The need to include vulnerable groups in the labour market remains an issue, and migration to Europe and the growing number of new arrivals increase the need to improve integration. Varying levels of participation in the workforce and employment among people born outside the Nordic region comprise a challenge for the Nordic countries. An ageing population is working for longer, but this also entails a challenge to ensure a sufficient supply of labour and to meet a growing need for welfare services in the Nordic countries. This particularly applies in those parts of the Nordic region with declining populations of working age.

The Nordic co-operation will focus on long-term challenges. However, the co-operation will also allow flexibility so that, where necessary, there can be a focus on challenges relating to the economic cycle and other unforeseen events that may occur during the programme period.

In many ways, the challenges and trends we can see ahead of us are interlinked, and therefore difficult to distinguish clearly. Overall, there are grounds for arguing that the Nordic labour markets are entering a period that may have a great influence on labour and society in the future. Therefore, there can be potential value in addressing these challenges through the Nordic cooperation. Follow-up and co-operation around broader and more integrated investigations, statistics, and relevant future-scenario analyses can help in this work, together with continuous exchange of experiences, professional and political discussions, and mutual learning between the Nordic countries. 


\section{FOCUS AREA 1}

Strengthen the matching between supply and demand regarding a skilled workforce and increase participation in the labour market, particularly for vulnerable groups.

A main priority for the co-operation in employment and the labour market is to promote the greatest possible participation of women and men in working life, and the lowest possible number of people who are permanently outside the labour market.

Important objectives in employment and the labour market are:

Increase participation in the workforce, particularly among vulnerable groups in the labour market. This entails a focus on faster and more efficient integration in working life of young people, long-term unemployed people, older people, and immigrants. Emphasis will also be placed on reducing sick leave among employees, and increasing the participation in working life of people with reduced capacity to work and disabilities. Mental health trends, particularly among young people, are a concern and require attention. It is important to ensure that those people entering employment can retain their jobs, and that older employees remain in the workforce for as long as possible. Capacity will also be increased by giving those people who already have part-time work, and who wish to increase their availability for work, the opportunity to work more. Involvement of and co-operation with various relevant actors on the labour market is important for attaining the objective of increased employment.

\section{Strengthen the matching between} supply and demand in the workforce. Focus will be placed on how to strengthen the matching of supply and demand in the labour market in terms of reducing bottlenecks and ensuring better use of labour resources. Close matching between those looking for work and those looking for labour requires that job centres are aware of the needs of the labour market and have contact with both jobseekers and employers. Approval of qualifications and skills learned through experience continue to be current themes, together with requirements for professional and geographical mobility and expectations about the individual's activity and participation. 


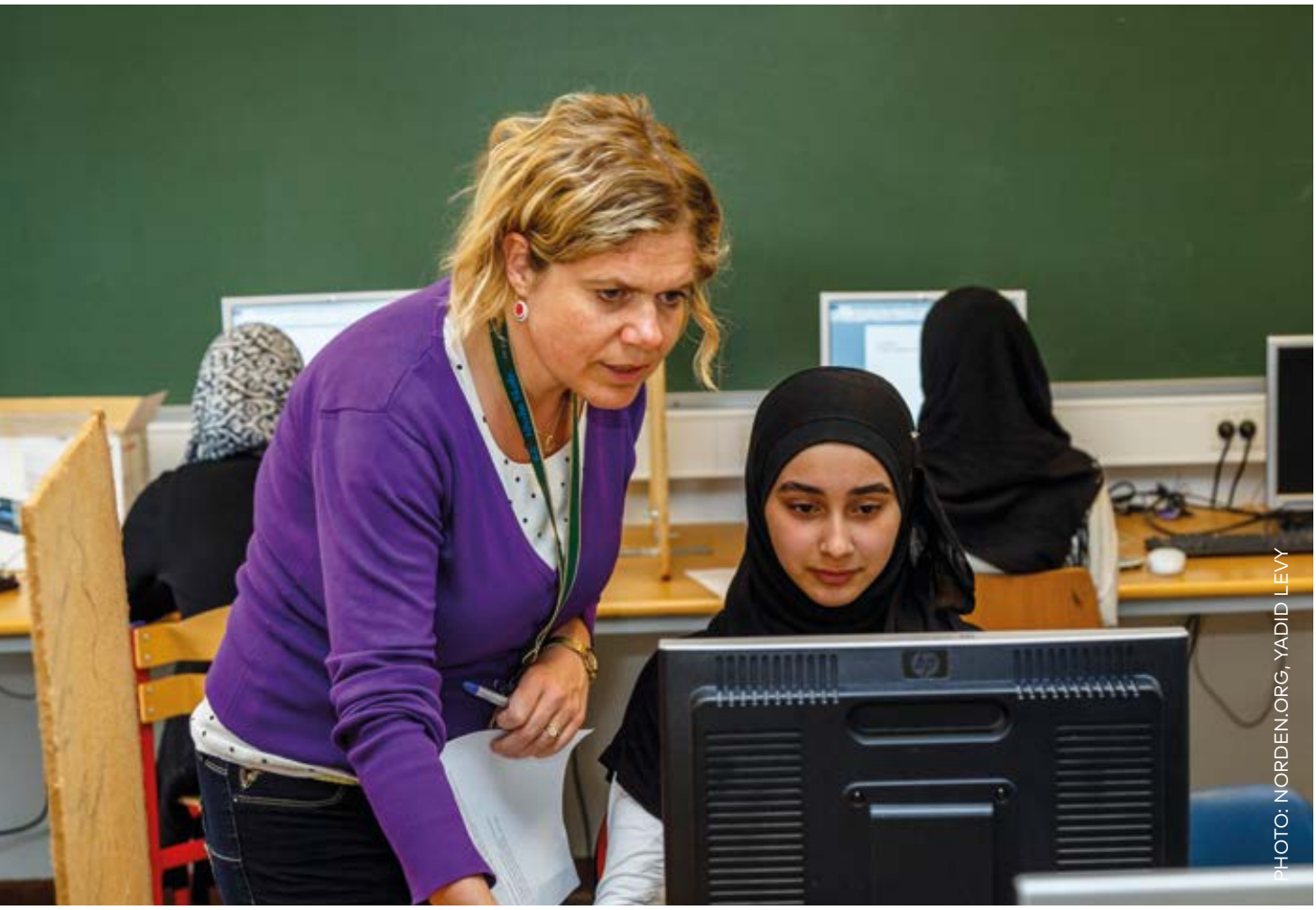

Focus will be placed on combating unemployment, improving opportunities for employment, and counteracting long-term periods of unemployment. Young people, immigrants, and people with low levels of formal skills are examples of groups in society at particular risk of unemployment. People with disabilities that reduce capacity for work are more often outside working life, even if they would like to work. Focus will be placed on disabilities that make it difficult for these groups to participate, and on measures that are effective and help more people into work. Here, it is also important to focus on how to reduce obstacles and strengthen opportunities on the labour market, how to create incentives to work, and how to create a good balance between work, income and welfare services in the Nordic countries.

\section{Promote development of skills adapted} to labour market needs. Focus will be placed on the best possible ways to develop workforce skills in terms of meeting the increased needs for adaptation, and ensuring that the workforce continually has the qualifications that the labour market needs. The need for skills development applies particularly to people with low levels of formal qualification and weak 
basic skills, and for people with skills that do not correspond to the needs of the labour market. These groups are also more vulnerable to changes and developments in the labour sector, including the technological development. The educational system also plays a key role in creating a higher basic level of education and in ensuring that young people complete the necessary education. At the same time, most adults will need to learn new skills throughout life to secure their connection to the labour market - regardless of age, gender and educational background. This makes it important to direct attention towards lifelong learning, learning in working life and in workplaces, and enabling in-service training.

\section{FOCUS AREA 2}

Ensure a healthy work environment for both women and men, such as by preventing work-related health problems and workplace injuries, and abolishing unacceptable working conditions.

Important objectives for the work environment (occupational health and safety) are:

\section{Promote a well-functioning and} appropriate work environment. The demographic trend and society's future needs for a workforce require focus on the companies' preventive work relating to the work environment. Well-functioning and targeted work at local level is vital for reducing sick leave, extending work careers, and increasing the degree of participation in working life among vulnerable groups. The work will be based on the individual companies' operation and production, which enables a work environment in which employees can conduct their work in a productive and meaningful way without risk of injury and ill-health. It is important to promote the chances of young families and individuals obtaining employment positions that enable a better balance between working life and private life, and to mobilise older employees so that they continue working until an older age. Greater knowledge is needed about what stimulatory measures and follow-up at individual workplaces and individual work environments are necessary to attain these objectives. There are big differences in how individual organisations work with this, so there is potential for improvements in the area. Increasing understanding for the positive effect of the work environment 
on productivity, and the measures that particularly contribute to, for example, reducing sick leave and early retirement, will be vital.

\section{Ensure a good physical and mental work} environment. Focus will lie on how to utilise much of the individual employee's resources and ensure a healthy and sustainable work environment for everyone throughout their work careers. Attention will be directed towards the major challenges, including statistics relating to sick leave and early retirement, to which musculoskeletal diseases and psychosocial factors are key contributors. Attention will also be directed towards particularly vulnerable groups, such as young and older employees, minority groups, and employees with reduced capacity for work, and particularly arduous professions and sectors. The EU work environment strategy will also provide an important basis for the Nordic cooperation in the area.

\section{Abolish unacceptable working conditions and social dumping/labour criminality.}

Focus will be directed on how to further develop the Nordic region as an attractive labour market with high levels of professional skills and a high standard in terms of employment conditions and work environment, and a labour market that also helps attract the necessary foreign labour. There will also be a strong focus on preventing low-wage competition and greater labour migration leading to unacceptable work conditions, wage dumping and discrimination in the Nordic labour market. This is the theme with great potential for exchanging both information and experiences about efficient crime prevention initiatives and measures, where the opportunities for stronger practical co-operation between relevant Nordic agencies can be considered.

\section{Further development of work environment strategies and supervision.} Focus will be directed towards exchange of experiences and knowledge concerning effective work environment strategies and methods of supervision, including the EU strategy on work environment and other relevant prioritisations. An important part of the co-operation will comprise acquiring more concrete and practical research-based knowledge about which work environment strategies and forms of supervision are effective and produce results out in the organisations. 


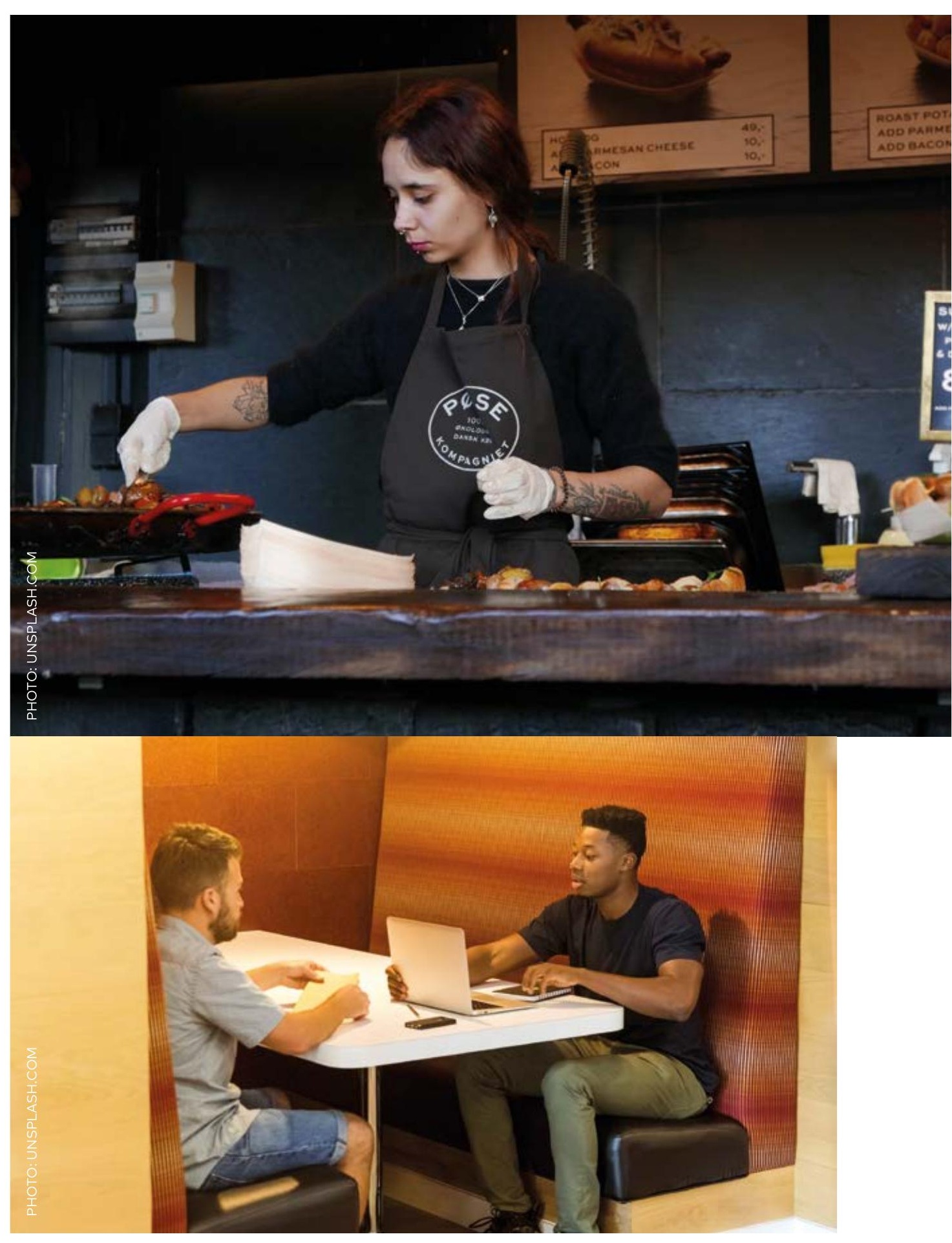




\section{FOCUS AREA 3}

Ensure a good balance between employee protection and flexibility, and utilise the Nordic tripartite model for labour.

Work environment and labour law are areas that are closely linked, so it is important to see the objectives in Focus Areas 2 and 3 in context. Important objectives to improve labour law are:

\section{Ensure a balance between employee protection and flexibility in the labour} sector. In the future, working life will offer new work forms and new tasks for the workforce. These new ways of organising labour will have consequences for employment forms and relationships in labour law, so it will be important to ensure that this does not lead to negative consequences, either for the individual, for different organisations, or for the economy. A renewed focus on how to create and further develop models for employee protection and flexibility in working life, and ensuring a balance, will be prioritised.

\section{Ensure well-regulated conditions in the} labour market. Focus will be placed on maintaining and further developing a professional labour sector in the Nordic region and, in collaboration with the parties in the sector, preventing and combating discrimination, social dumping/labour-related criminality, and the grey economy.

\section{Adapt and develop the Nordic labour} model. The tripartite labour model is central in the Nordic countries. One priority in the Nordic co-operation will be to support and develop the Nordic labour model and tackle the challenges facing the model. This will be done through exchange of knowledge and cooperation, for example in contact with the EU and other relevant international bodies. Another aim is to ensure that the competitiveness and sustainability of the model is retained in future work forms. The degree of organisation and the position and strength of the labour market parties on the Nordic labour market are important issues in this context.

\section{FOCUS AREA 4}

Strengthen integration, equal opportunities, and mobility on the Nordic labour market.

Important cross-sector objectives in this area are: 
Promote integration of new arrivals and immigrants. During the co-operation programme period, particular attention will be directed towards initiatives to help immigrants to become established on the labour market. This is because employment comprises a main element in ensuring successful integration and is an important component in ensuring sustainability in the welfare systems. There is a need to attain rapid, efficient and flexible routes into working life. The participation of new arrivals in initiatives that enable them to become established in working and societal life, dialogue with labour market parties and voluntary organisations, and partnership between the public and private sectors, are important components in an efficient integration policy. The participation of both parents in working life is also a significant aspect of promoting integration of children and young people in society.

\section{Promote equal treatment and equality in} the labour sector. Co-operation on labour will focus on promoting equal treatment in terms of gender, ethnicity, disabilities, etc. and hindering segregated labour markets. Here, the balance between working and private lives is a key factor. In this context, it is also important to facilitate increased participation in the labour market among immigrant women, and to direct focus on measures that make it easier to combine work, education and family. Co-operation on labour will also focus on working to prevent discrimination on the grounds of age, gender, ethnicity, national origin, etc.

Ensure mobility and reduce and prevent new obstacles to cross-border freedom of movement in the Nordic region. The free, Nordic labour market has been successful for over 60 years, and it is important to maintain and develop it in the future. Work in the sector will focus on constantly improving mobility in the Nordic labour market by removing obstacles to cross-border freedom of movement and preventing new ones arising. This work will proceed by considering the $\mathrm{EU}$ and the frameworks the EU sets up. The importance of mobility, particularly in relation to sparsely-populated areas, and the challenges they face, including imbalance in needs for skilled labour, is important to examine in more detail. 


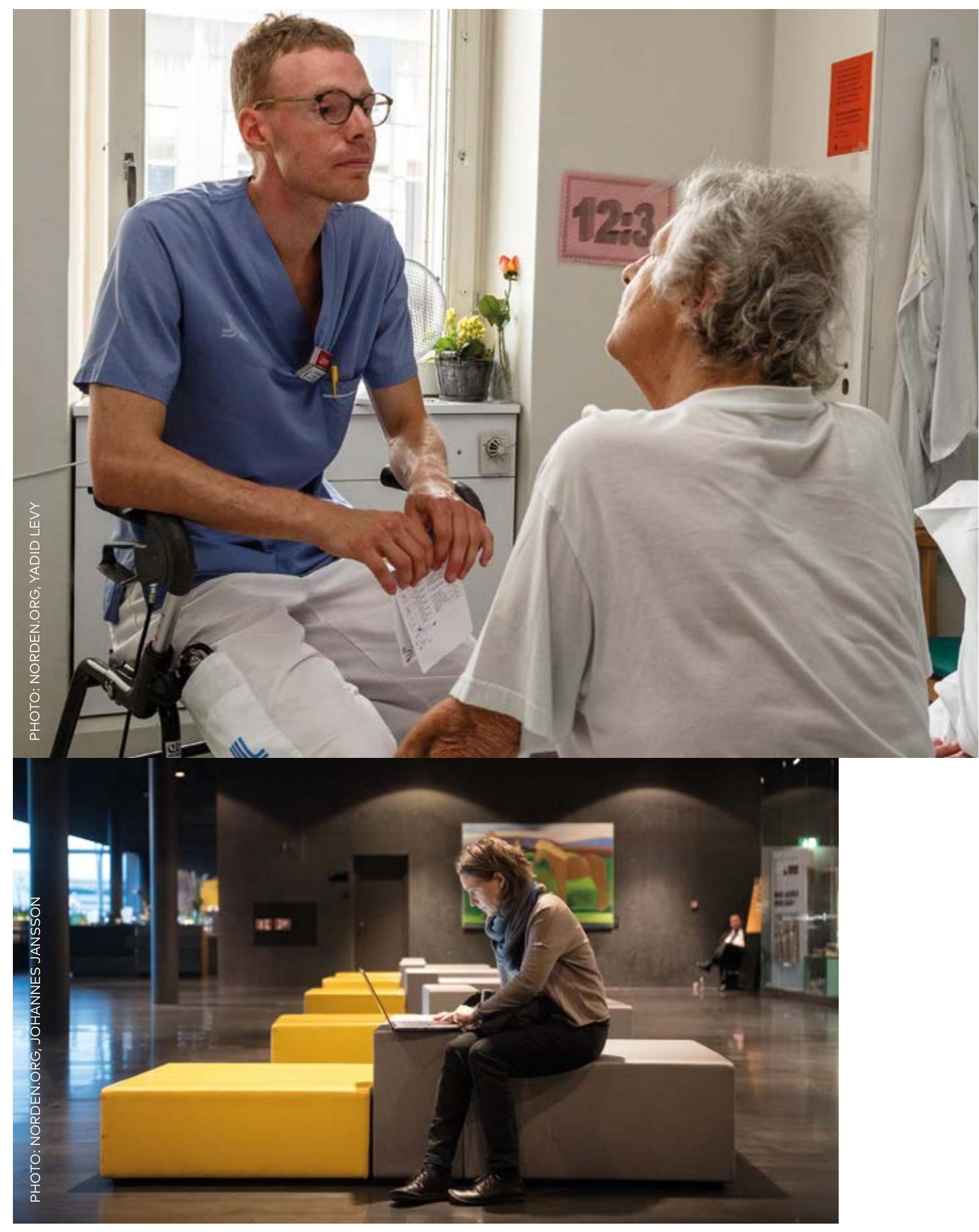




\section{Co-operation with the EU and other international actors}

The sector will continually work to strengthen the co-operation with the EU and monitor future legislative initiatives from the European Commission. EU issues of common Nordic interest are constantly raised and discussed in meetings of the Council of Ministers, the Committee of Senior Officials, and the standing committees. An important part of this work is to remove obstacles to cross-border freedom of movement and prevent new ones arising.

In particular, the Labour Law Committee specialises on working with EU issues, and focuses on both the early legislative phase, ongoing negotiations, implementation of EU legislation, and decisions from the EU courts, and other similar matters. In addition, the Nordic Social Security Group has been asked by EK-A to monitor developments in the above areas to prevent new obstacles to cross-border freedom of movement arising. The Nordic-Baltic-Polish EU information group monitors the EU work on labour policy.

In addition to the $\mathrm{EU}$, there are other important international actors that are important for the Nordic co-operation on labour. The International Labour Organisation (ILO) is the UN's professional body for employment and work environment issues. During the introductory phase of the cooperation programme on labour, it will be important, for example, to monitor and influence the work relating to Future of Work, which is part of the ILO's centenary during 2019. This centenary will give the Nordic countries, and the Faroe Islands, Greenland and Åland, the opportunity to contribute joint Nordic views and good practice regarding labour in the future and will also form the basis of continued co-operation.

The Organisation for Economic Cooperation and Development (OECD) has a major focus on measures to generate growth and employment. The expertise and analyses of the OECD on labour market issues can also contribute to the Nordic co-operation on labour.

Where relevant, representatives from organisations such as the EU, OECD and ILO will be invited to participate in meetings, conferences, etc. 


\section{Organisation in the sector}

The Council of Ministers for Labour (MR-A) has the overall responsibility for Nordic co-operation on labour, and is an important forum for discussion and exchange of experiences among the Nordic ministers responsible for employment, labour law and work environment on how to best tackle common challenges regarding labour.

The co-operation is organised by the Committee of Senior Officials for Labour (EK-A), which sets guidelines for, and allocates, the budget of the MR-A. A flexible organisational structure is vital so that the Nordic co-operation on labour can efficiently initiate and follow up on current issues. EK-A has appointed three standing committees - the Labour Market Committee, the Work Environment Committee, and the Labour Law Committee - and appoints ad hoc committees as and when necessary. In addition to the committees, there is also the NordicBaltic-Polish EU Information Group, which mainly monitors the EU work on labour market policy, work-related legislation, and work environment.

The committees and working groups play an important role for exchanging knowledge and experience between the countries in the respective areas of responsibility. They will also provide input to MR-A and EK-A.

In addition, the Nordic Institute for Advanced Training in Occupational Health (NIVA) in Helsinki is part of the Nordic co-operation on labour (cf. page 20). The Nordic Council of Ministers for Labour also co-funds the Nordjobb programme, a mobility and development programme for young Nordic citizens wishing to work in another Nordic country (www.nordjobb.net). The Council of Ministers also funds an information programme, in the Scandinavian languages and English, on the labour sector in the Nordic region (www.arbejdslivinorden.org).

The formal co-operation also creates important networks between Nordic officials in the labour field, from which the countries can benefit greatly in concrete situations. It must be pointed out that, in addition to the formal Nordic co-operation within the Nordic Council of Ministers, there is also extensive informal Nordic collaboration, often with a long history. 

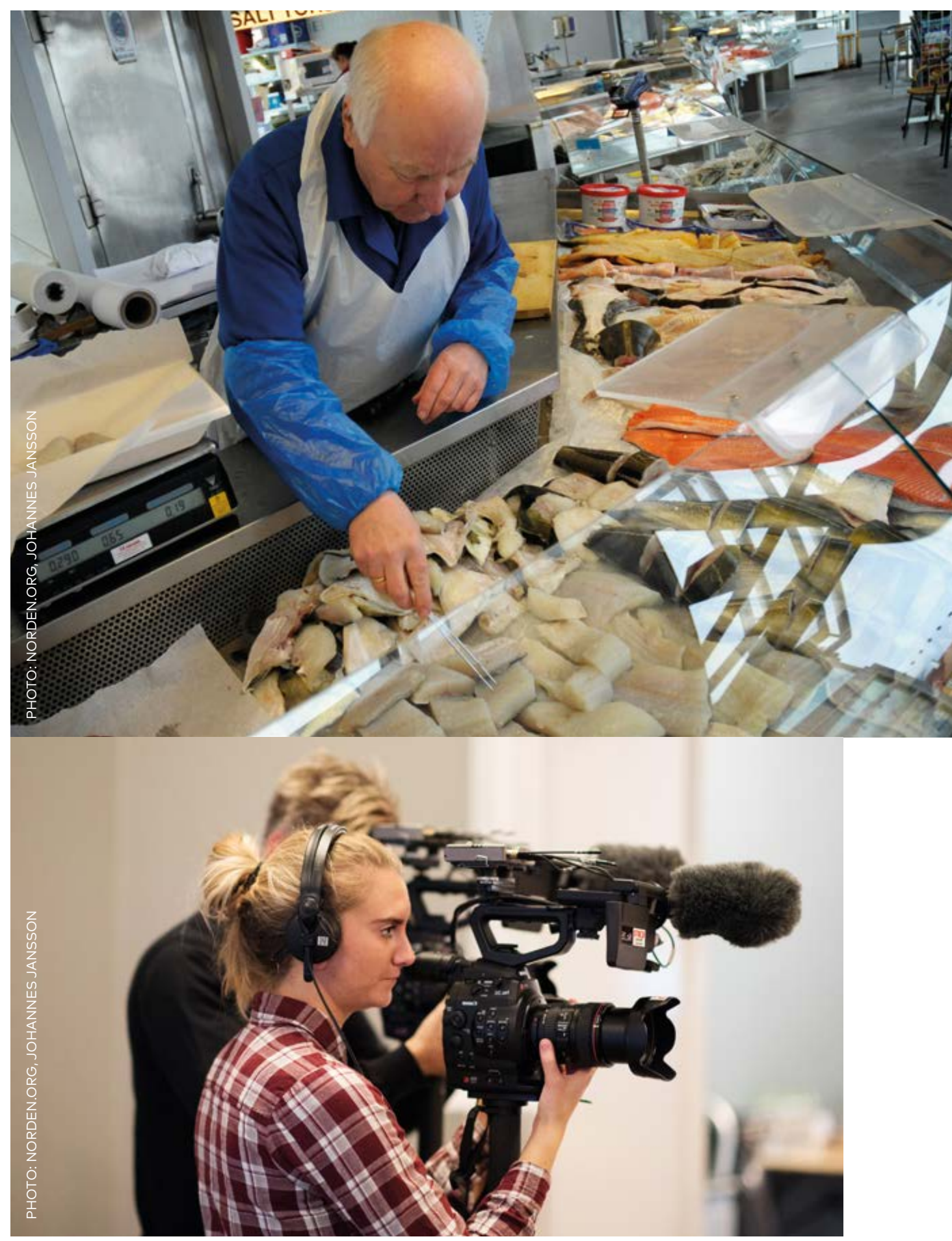


\section{Nordic Institute for Advanced Training in Occupational Health - NIVA}

The Nordic Institute for Advanced Training in Occupational Health (NIVA) is a Nordic institution in the Nordic co-operation on labour, working under the Nordic Council of Ministers (www.niva.org). The work of NIVA is based on a strategic mandate decided by EK-A.

NIVA's main task is to act as a forum for disseminating knowledge in the fields of occupational health and work environment. NIVA will create dialogue on important and pioneering work environment issues, which will help to improve working life in the Nordic region. NIVA will also generate Nordic added value by organising symposia, workshops and seminars at high academic level, particularly in areas where an individual country is lacking a critical mass.

Occupational health and work environment is a multidisciplinary field where the challenges change in line with changing working life. Special challenges in the coming years will reflect NIVA's activities in the period until 2021, including the ageing working population, psychosocial risks in working life, development of new technologies, efficient prevention of accidents at work, and future labour forms and their effects on working conditions. 


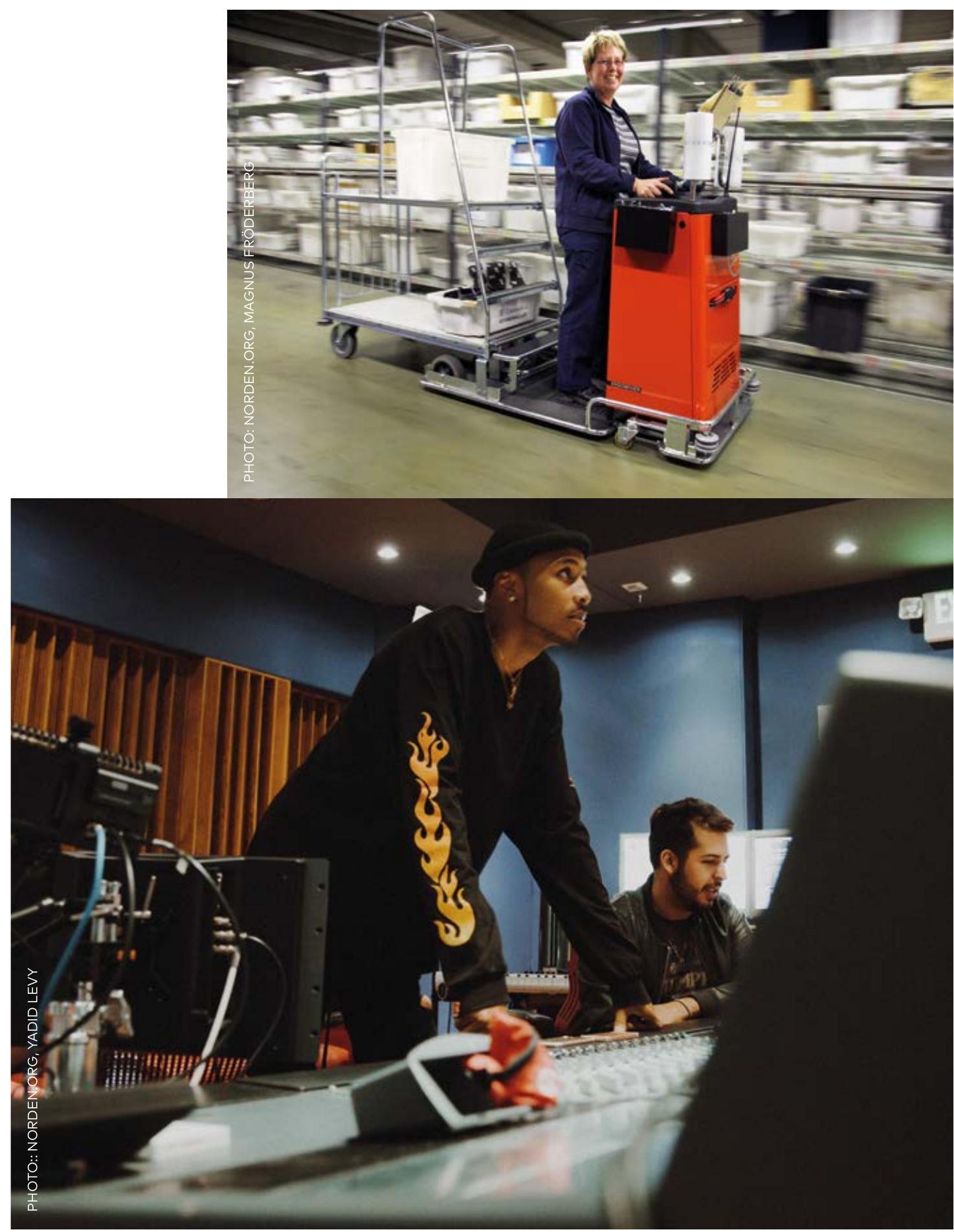




\section{Implementation of the co-operation programme}

The challenges and focus areas identified in this co-operation programme will be key areas for the Nordic co-operation on labour 2018-2021.

The co-operation programme is reflected in the budget for MR-A, and will govern and set conditions for the activities of the three committees and for the rest of the sector.

In the sector, particular emphasis will be placed on holding a common, continual and frequent dialogue and exchanging information that will help to generate new knowledge and new initiatives. The dialogue will take place between several actors, such as labour market parties, research environments, and relevant agencies and actors. The cooperation can give inspiration to national policy development within national frameworks, but can also form a basis for coordinating views where they are deemed relevant and valuable.

The co-operation programme will be made tangible and will be implemented, particularly in conjunction with presidency activities and in the committees' plans of action. The standing committees have limited project funds at their disposal, and these are primarily used to improve the knowledge base for exchanging experiences. This is done, for example, by reviewing and analysing similarities and differences between the measures in the Nordic countries, and the effects of these. The projects will help in the implementation of the co-operation programme.

Several Nordic conferences will be held on current themes in the labour sector. The conferences will provide a basis for exchange of knowledge and experiences between the countries, create meeting places, and promote networking and development work.

Dialogue will take place largely between MR-A, EK-A, relevant committees, and the Secretariat of the Nordic Council of Ministers, and with parties on the labour market. The parties are invited to provide input to the co-operation programme and will usually be invited to participate in tripartite discussions on current labour sector themes in conjunction with the annual meetings of MR-A. Other actors, councils, and committees will continually be invited to participate when relevant.

In addition, the sector is expected to participate in cross-sector initiatives initiated by, for example, the prime ministers, the ministers for Nordic co-operation (MR-SAM), or the Nordic 


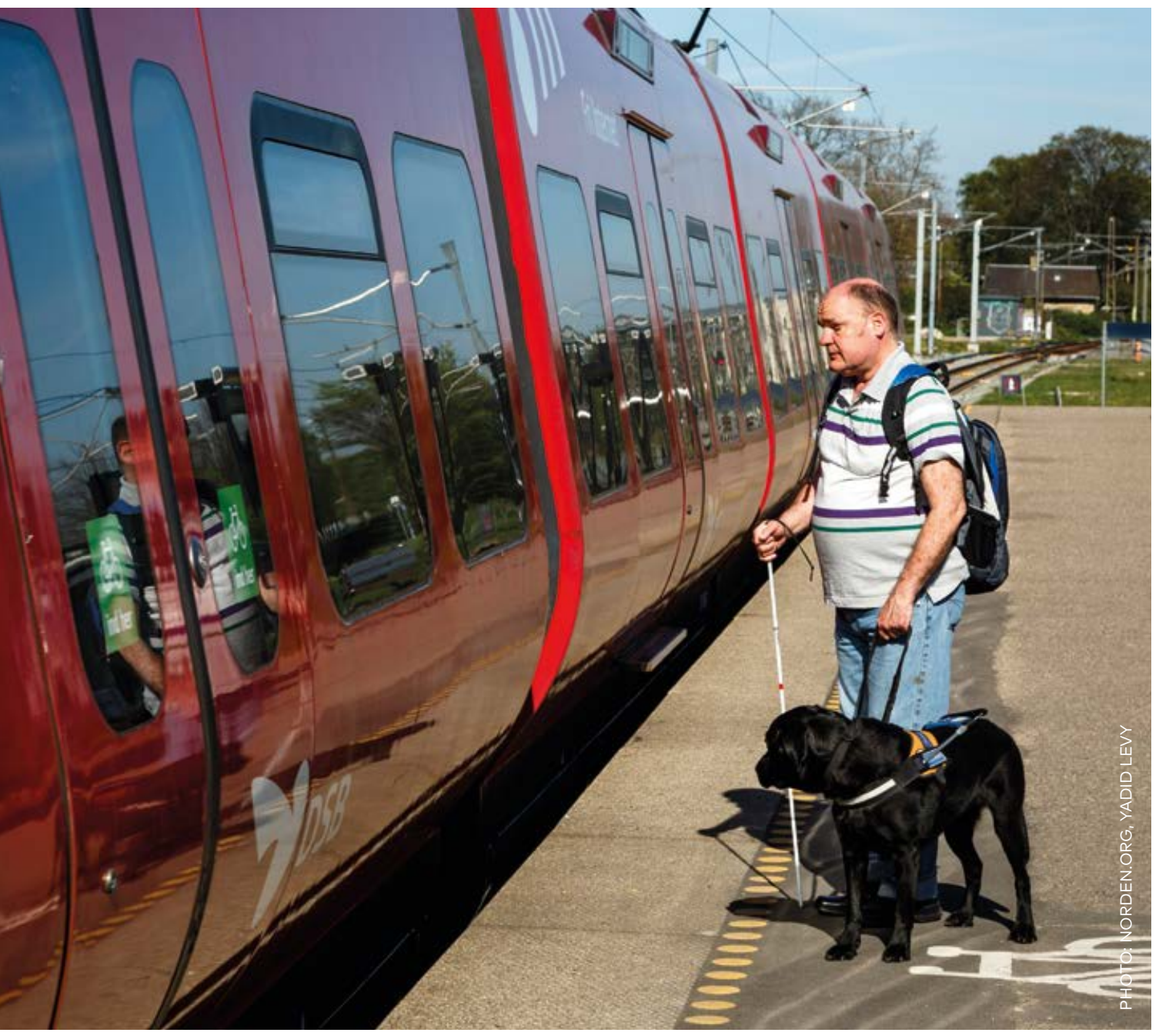

Council. In all activities, the co-operation will integrate the strategy of the Nordic Council of Ministers for sustainable development and, where relevant, also include gender equality, children and young people, integration, and the disability perspective as described on page 6 . The working life sector will also co-operate with other sectors in the Nordic Council of Ministers, particularly the Nordic Council of Ministers for Health and Social Affairs (MR-S), the Nordic Council of Ministers for Sustainable Growth (MR-Vækst) and the Nordic Council of Ministers for Gender Equality (MR-JÄM). The experiences of the cooperation programme will be evaluated before the end of the programme period in 2021. 


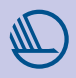

Nordic Council of Ministers

Nordens Hus

Ved Stranden 18

1061 Copenhagen $\mathrm{K}$

www.norden.org

The common labour market comprises a cornerstone in the Nordic co-operation. A large, skilled workforce is our most important resource, and forms the foundation for a competitive Nordic labour market and for development of the Nordic welfare societies.

At the same time, the Nordic labour markets are facing major changes because of, for example, demographic change, increased globalisation, technological development, and international competition.

The co-operation programme on labour 2018-2021 identifies several important challenges relating to the labour sector, and shows how the Nordic co-operation can help to address these. 